\title{
THICKNESS INFLUENCE ON ABSORBING PROPERTIES OF STRATIFIED COMPOSITE MATERIALS
}

\author{
IULIANA IAȘNICU (STAMATE) ${ }^{1 *}$, OVIDIU VASILE ${ }^{2}$, RADU IATAN $^{3}$ \\ ${ }^{1}$ Gheorghe Asachi Technical College, Bucharest, 24 Aleea Pravat, sector 6, \\ 061569 Bucharest, Romania \\ ${ }^{2}$ Department of Mechanics, University Politehnica of Bucharest, 313 Splaiul Independentei, \\ sector 6, 060042 Bucharest, Romania \\ ${ }^{3}$ Department of Process Equipment, University Politehnica of Bucharest, 313 Splaiul \\ Independentei, sector 6, 060042 Bucharest, Romania
}

\begin{abstract}
Plates known as sound absorbing materials: textiles recovered fabrics plus polyethylene are made layered composite material intended to be used to encapsulate industrial engines, as sources of noise in the production departments. Influence of thickness sound-absorbing material can be supported by the values obtained for the absorption coefficient, but it can be studied as a study case in the anechoic chamber, where the sound pressure level is measured with a sound level meter. Cases captured: a free engine; the engine placed in a metallic cube and motor inserted; metal cube that was doubled separately with one material and then with the composite material proposed. For each situation are eight determinations on the perimeter of a circle with a radius of one meter from the source of the noise. Plot a graph of experimental results that support the idea: greater thickness of the layer of material will cause a better absorption of noise.
\end{abstract}

Keywords: thickness, polyethylene, absorption, plate, stratified composite materials

\section{INTRODUCTION}

The study of acoustics refers to the generation, propagation and reception of mechanical waves and vibrations. The wave of sound propagation consists of alternating compressions and rarefactions that are detected as changes in the sound pressure level by a receiver. Noise is a complex sound, a mix of different frequencies. Generally, people can hear the acoustic waves between 20 and 20,000 Hz. Under $20 \mathrm{~Hz}$ they are infrasonic and over 20,000 $\mathrm{Hz}$ they are ultrasonic. Noise is a risk factor that has harmful effects on the human body [1], which can lead to: disorders of the auditory organ; disorders of various organs and body apparatuses; the reduction of labor productivity; the reduction of intelligibility of speech [2].

Human development amply illustrated the continuing desire to find solutions and products that meet the requirements of use and safety. Practical manifestation conditions could be satisfied through the use of advanced materials. Natural resources are not inexhaustible, so are present natural ways to find new compositions, drawing on and combining the pure - the primary recyclable, but that ensure both strength and aesthetics. Since ancient times, natural and/ or artificial composites have gained importance; it is at the same time, an old concept, but also new and very topical.

\footnotetext{
* Corresponding author, e-mail: yulyanastamate@yahoo.com

(C) 2015 Alma Mater Publishing House
} 
In the study of composite materials, there is highlighted the interest in using recycled materials [3-7]. It studies the contribution that can have recycled textiles and other materials that can be merged to form a layered composite can be used for sound insulation or noise sources encapsulation. It is often mentioned the important role of various types of fiber insertions, for which reason their impact was monitored, both for textile fibers - bamboo, jute [8-11] and for other types of fibers, for example, wood fiber or tea ones [7, 12]. The composite materials to be made are intended to be used as materials to carry out the proofing of noise sources; references to this area of interest are to be found in [13-15] works.

Studying textile plates recovered and polyethylene plates in order subsequently to achieve the layered composite materials containing these plates. Study of plates is made from the point of influence of the thickness of the material used to encapsulation on sound-absorbing properties.

\section{PRESENTATION OF THE TYPES OF MATERIALS AND THE MEASURING SYSTEM}

First it analyzes the sound pressure level due to engine operation in an anechoic chamber - P0; Figure 1a. Carry out determinations in metallic cube with a side of $65 \mathrm{~cm}$ and the thickness of $7 \mathrm{~mm}$ - PI; Figure 1b. It then studies the situation when the metallic cube is doubled with a plate fabric recovered textile material with the thickness of $10 \mathrm{~mm}$ - PII; Figure 1c. The anechoic room has been designed and manufactured according to ISO 3745 [16].

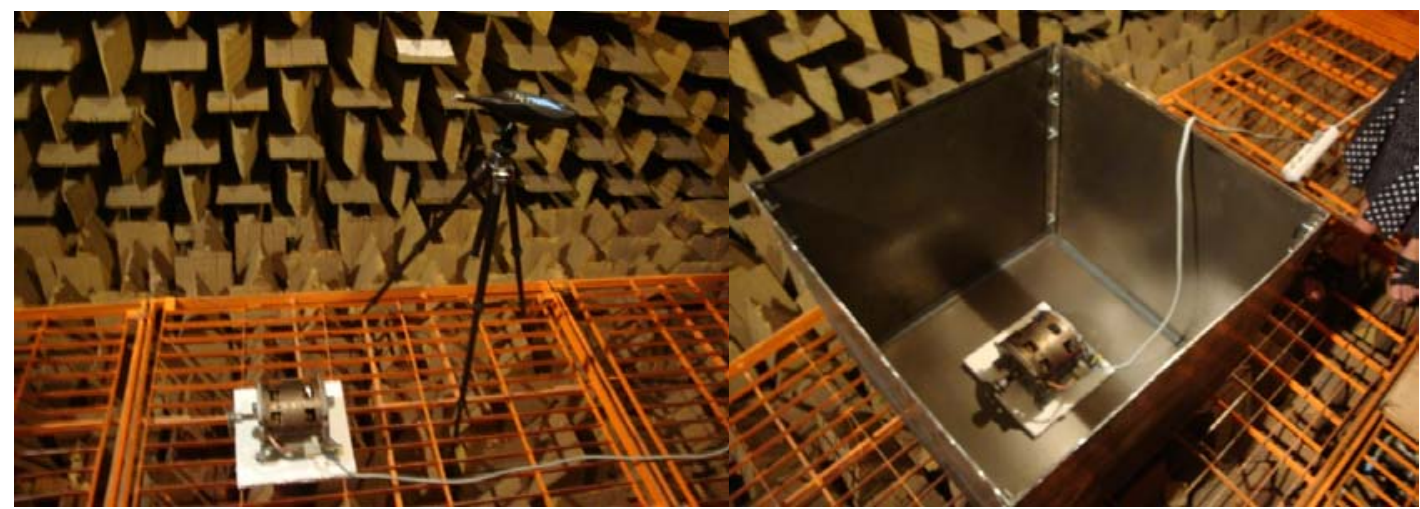

a)

b)

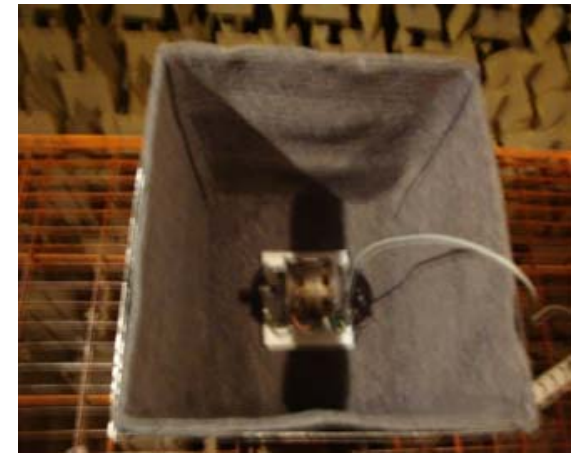

c)

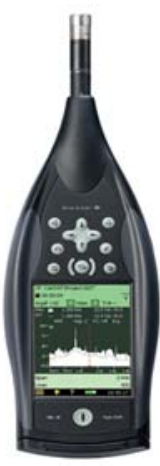

d)

Fig. 1. The cases studied in the anechoic chamber (a-c) and the portable analyzer Bruel\&Kjaer type 2270 (d).

The anechoic room is a laboratory environment structured to minimize the reflection of acoustic signals by chamber walls. The absorption coefficient $\alpha=99 \%$ of the walls in the frequency band from $150 \mathrm{~Hz}$ to $20,000 \mathrm{~Hz}$. The used frequency band were $1 / 3$ octave $(2 \mathrm{~Hz}-16 \mathrm{kHz})$.

For the experiment were necessary following appliances and devices: Bruel\&Kjaer portable analyzers type 2270 plus a set of internal software modules, including frequency analysis and signal recording (logging) and sound to his playing - Figure 1d. 
Sound Level Meter Type 2270 is a versatile, modular platform with multiple modules optional applications such as frequency analysis, FFT, advanced logging (profiling) and sound recording. Sound Level Meter Type 2270 twochannel measurement allows measurements: sound intensity, in accordance with IEC 61043, sound power measurements and acoustic measurements on two channels enclosure buildings.

Using the appliance:

- Real-time frequency analysis in octave and $1 / 3$ octave bands;

- Documentation of measurements by recording sound to playback signal.

\section{SOUND ABSORBING MATERIAL CHARACTERISTIC VALUES}

Determination of sound power and directivity are full characteristic of sound sources. In the case of free acoustic field, conducted in anechoic chamber, representing $L_{W A}$, weighted sound power level is calculated from $L_{p m}$, the average sound pressure level on measurement surface $S$, using the relationship [17- 20]:

$$
L_{W A}=L_{p m}+10 \log \left(\frac{S}{S_{0}}\right)+K, \quad[\mathrm{~dB}(\mathrm{~A})]
$$

where:

$$
L_{p m}=\frac{1}{8} \sum_{i=1}^{8} L_{p i}
$$

$\mathrm{S}_{0}=1 \mathrm{~m}^{2}$ is the area of the reference surface;

$\mathrm{S}=\pi \mathrm{r}^{2}=3.14 \mathrm{~m}^{2}$ if it studied the situation when $\mathrm{r}=1 \mathrm{~m}$;

$\mathrm{K}$ is the correction coefficient of the ambient pressure and temperature reference conditions of $20^{\circ} \mathrm{C}$ and $1000 \mathrm{~Pa}$; it choose $\mathrm{K}=0$.

$$
L_{W A}=L_{p m}+10 \log 3.14=L_{p m}+4.97
$$

Weighted sound pressure level is calculated using relationship [20]:

$$
L_{p m A}=10 \cdot \log \left(\frac{1}{n} \sum_{i=1}^{n} 10^{0.1 \cdot L_{p i A}}\right),[\mathrm{dB}(\mathrm{A})]
$$

where: $L_{p i A}$ is the $A$ weighted sound pressure level, in $\mathrm{dB}(\mathrm{A})$, for the $n$ measurement points.

Determination directivity curve: the sound field corresponding to a directional sound sources can be characterized by a directivity factor $\mathrm{D}_{\theta \mathrm{i}}$ source, or a directivity index $\mathrm{D}_{\mathrm{q}}$. For omnidirectional source located in the open field there is the following relationship linking the sound pressure level and power level [20]:

$$
L_{p}=L_{W}-20 \cdot \log d-11,[\mathrm{~dB}(\mathrm{~A})]
$$

where $\mathrm{d}$ - source-receiver distance, $[\mathrm{m}] ; \mathrm{d}=1 \mathrm{~m}$.

For omnidirectional source located in the open field, each doubling of the distance the sound level decreases by $6 \mathrm{~dB}$. In the case of free acoustic field, conducted in anechoic chamber, sound pressure level measured in the eightpoint lead directivity factor calculation with formula [20]:

$$
D_{\theta i}=L_{p i}-L_{W}+20 \cdot \log d+11
$$


where: $D_{\theta i}$ are directivity factor, dimensionless unit.

\section{EXPERIMENTAL RESULTS}

In the experiment, four situations are monitored to determine the sound pressure level in the 8 point determination, treated at $45^{\circ}$ from one another. The results are summarized in Table 1.

Table 1. Experimental results of sound pressure level.

\begin{tabular}{|c|c|c|c|c|c|c|c|c|c|}
\hline Sample & $\begin{array}{c}L_{p 1} \\
{[\mathrm{~dB}(\mathrm{~A})]}\end{array}$ & $\begin{array}{c}L_{p 2} \\
{[\mathrm{~dB}(\mathrm{~A})]}\end{array}$ & $\begin{array}{c}L_{p 3} \\
{[\mathrm{~dB}(\mathrm{~A})]}\end{array}$ & $\begin{array}{c}L_{p 4} \\
{[\mathrm{~dB}(\mathrm{~A})]}\end{array}$ & $\begin{array}{c}L_{p 5} \\
{[\mathrm{~dB}(\mathrm{~A})]}\end{array}$ & $\begin{array}{c}L_{p 6} \\
{[\mathrm{~dB}(\mathrm{~A})]}\end{array}$ & $\begin{array}{c}L_{p 7} \\
{[\mathrm{~dB}(\mathrm{~A})]}\end{array}$ & $\begin{array}{c}L_{p 8} \\
{[\mathrm{~dB}(\mathrm{~A})]}\end{array}$ & $\begin{array}{c}L_{p m} \\
{[\mathrm{~dB}(\mathrm{~A})]}\end{array}$ \\
\hline P0 & 55.84 & 56.11 & 51.76 & 55.79 & 54.86 & 56.34 & 56.33 & 51.77 & 54.85 \\
\hline PI & 46.13 & 43.84 & 45.85 & 44.80 & 46.62 & 47.07 & 47.44 & 45.99 & 45.97 \\
\hline PII & 34.50 & 32.08 & 35.22 & 34.08 & 36.91 & 34.65 & 38.67 & 34.08 & 35.02 \\
\hline
\end{tabular}

The value for sound power, $L_{W A}$ are: for $\mathrm{P} 0$ is $59.82 \mathrm{~dB}(\mathrm{~A})$; for $\mathrm{PI}$ is $50.94 \mathrm{~dB}(\mathrm{~A})$ and for PII is $39.99 \mathrm{~dB}(\mathrm{~A})$. Determine the source height of $40 \mathrm{~cm}$, as having a value of $73.8 \mathrm{~dB}(\mathrm{~A})$.

After calculating the sound, power goes directivity factor calculation (Table 2 for sample P0; Table 3 for sample PI; Table 4 for sample PII), which is then plotted (Figure 2 for sample P0; Figure 3 for sample PI and Figure 4 for sample PII) and interpreted. In these figures is plotted the plan distribution of sound pressure level and directivity factor in the 8 points $\mathrm{P} 1-\mathrm{P} 8$, positioned around the noise source from $0^{\circ}$ to $315^{\circ}$. As can be seen in the figure legends, the two curves have different scales of representation, and they are differentiated by color. In Figure 2 the blue represents the variation in sound pressure level between 48-58 level $\mathrm{dB}$, and with red is represented the variation of in plan directivity factor from 0 to 8 (dimensionless unit).

Table 2. Calculation of directivity for sample P0 - engine in the anechoic chamber.

\begin{tabular}{|c|c|c|c|c|c|c|c|c|}
\hline Measuring point & P1 & P2 & P3 & P4 & P5 & P6 & P7 & P8 \\
\hline$\theta_{\mathrm{i}}[$ degree $]$ & $0^{\circ}$ & $45^{\circ}$ & $90^{\circ}$ & $135^{\circ}$ & $180^{\circ}$ & $225^{\circ}$ & $270^{\circ}$ & $315^{\circ}$ \\
\hline $\mathrm{L}_{\mathrm{pi}}[\mathrm{dB}(\mathrm{A})]$ & 55.84 & 56.11 & 51.76 & 55.79 & 54.86 & 56.34 & 56.33 & 51.77 \\
\hline $\mathrm{D}_{\theta \mathrm{i}}$ & 7.02 & 7.29 & 2.94 & 6.97 & 6.04 & 7.52 & 7.51 & 2.95 \\
\hline
\end{tabular}

In all the graphs $D_{\theta i}$ is represented with red continuous line.

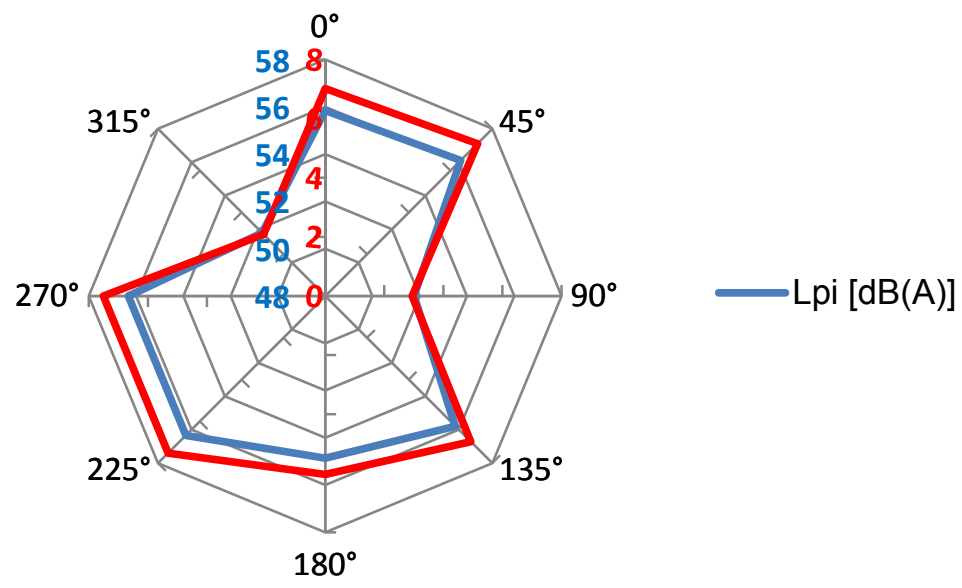

Fig. 2. Sound pressure level and directivity factor for sample P0.

As can be seen, the geometric shape of the curve of sound pressure level is not circular, if noise source does not produce the same level of noise in all directions, due to geometrical shape of the electric motor and the position of 
the respective components of the electric drive (position shaft, bearing position, the position of the cooling fan, engine mounting position etc.).

In case P0, when the sound pressure level determinations are made in the eight set points are obtained graphics for sound pressure level and directivity factor with the same form, with minimum values in the points P3 and P8 corresponding to the angles of $90^{\circ}$ and $315^{\circ}$. The maximum values are in points $\mathrm{P} 6$ and $\mathrm{P} 7$ corresponding to the angles of $225^{\circ}$ and $270^{\circ}$. The average value of measured sound pressure level is $54.85 \mathrm{~dB}(\mathrm{~A})$ and calculate sound power level are $L_{W A}=59.82 \mathrm{~dB}(\mathrm{~A})$.

Table 3. Calculation of directivity for sample P I - engine in the metallic cube.

\begin{tabular}{|c|c|c|c|c|c|c|c|c|}
\hline Measuring point & P 1 & P 2 & P 3 & P 4 & P 5 & P 6 & P 7 & P 8 \\
\hline$\theta_{\mathrm{i}}[$ degree $]$ & $0^{\circ}$ & $45^{\circ}$ & $90^{\circ}$ & $135^{\circ}$ & $180^{\circ}$ & $225^{\circ}$ & $270^{\circ}$ & $315^{\circ}$ \\
\hline $\mathrm{L}_{\mathrm{pi}}[\mathrm{dB}(\mathrm{A})]$ & 46.13 & 43.84 & 45.85 & 44.80 & 46.62 & 47.07 & 47.44 & 45.99 \\
\hline $\mathrm{D}_{\theta \mathrm{i}}$ & 6.19 & 3.90 & 5.91 & 4.86 & 6.68 & 7.13 & 7.50 & 6.05 \\
\hline
\end{tabular}

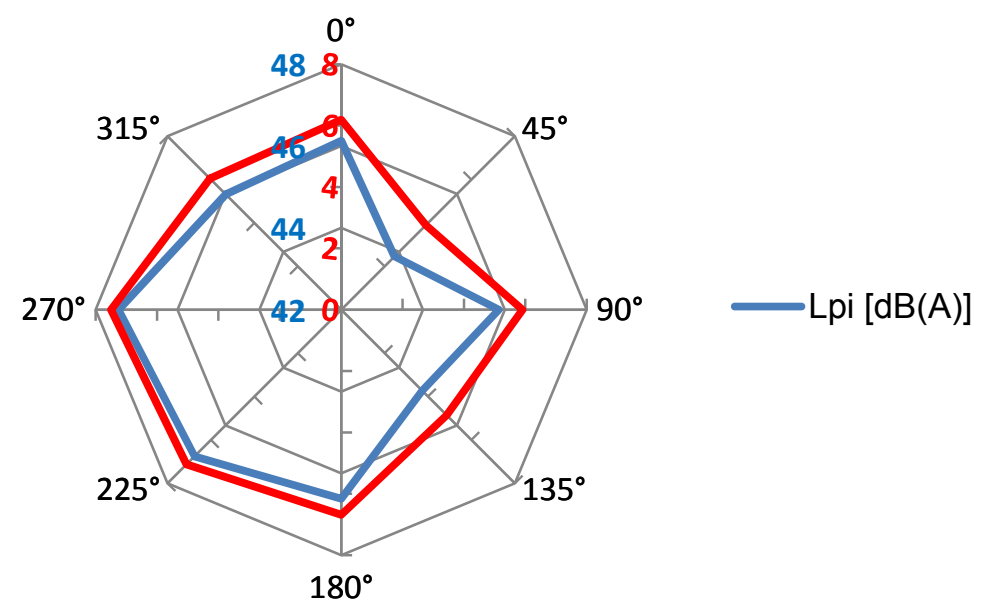

Fig. 3. Sound pressure level and directivity factor for sample PI.

After entering the engine in the metallic cube, determinations are made in the same measurement points. The minimum amount of sound pressure level and directivity factor is in point $\mathrm{P} 2$ corresponding angle of $45^{\circ}$ and obtain the maximum value at the point $\mathrm{P} 7$ on $270^{\circ}$. The average value of measured sound pressure level is 45.97 $\mathrm{dB}(\mathrm{A})$ and calculate sound power level are $L_{W A}=50.94 \mathrm{~dB}(\mathrm{~A})$.

By placing within a housing of an electric motor, initially thought the noise source, the housing itself will become a source of noise that includes the electric motor and air inside.

Also, in this case the IP by simply encapsulation with sheet metal with a thickness of $1.5 \mathrm{~mm}$, there is a noticeable change in sound pressure level variation, with relatively lower than the previous power value P0 influencing sound by decreasing from $59.82 \mathrm{~dB}$ to $50.94 \mathrm{~dB}, 8.88 \mathrm{~dB}$ difference appeared.

Table 4. Calculation of directivity for sample P II - engine in metallic cube + Plate fabric textile recovered.

\begin{tabular}{|c|c|c|c|c|c|c|c|c|}
\hline Measuring point & $\mathrm{P} 1$ & $\mathrm{P} 2$ & $\mathrm{P} 3$ & $\mathrm{P} 4$ & $\mathrm{P} 5$ & $\mathrm{P} 6$ & $\mathrm{P} 7$ & $\mathrm{P} 8$ \\
\hline$\theta_{\mathrm{i}}[$ degree $]$ & $0^{\circ}$ & $45^{\circ}$ & $90^{\circ}$ & $135^{\circ}$ & $180^{\circ}$ & $225^{\circ}$ & $270^{\circ}$ & $315^{\circ}$ \\
\hline $\mathrm{L}_{\mathrm{pi}}[\mathrm{dB}(\mathrm{A})]$ & 34.50 & 32.08 & 35.22 & 34.08 & 36.91 & 34.65 & 38.67 & 34.08 \\
\hline $\mathrm{D}_{\theta \mathrm{i}}$ & 5.51 & 3.09 & 6.23 & 5.09 & 7.92 & 5.66 & 9.68 & 5.09 \\
\hline
\end{tabular}

For sample PII - engine in metallic cube + Plate fabric textile recovered is observed as minimum are maintained point $\mathrm{P} 2$ corresponding angle of $45^{\circ}$ and as maximum point $\mathrm{P} 7$ on $270^{\circ}$. The average value of measured sound pressure level is $35.02 \mathrm{~dB}(\mathrm{~A})$ and the calculate sound power level are $L_{W A}=39.99 \mathrm{~dB}(\mathrm{~A})$. 
Is observed as the thickness of absorbing layer increases: PI $-7 \mathrm{~mm}$, PII $-7 \mathrm{~mm}+10 \mathrm{~mm}$ sound power values reach increasingly lower.

From here emerges the idea noteworthy, according to which the engine encapsulation would be a solution for noise reduction in the production departments. The more sound-absorbing material whereas the layer is thicker, the sound power that is transmitted in the environment is lower.

At the end of determination measured background noise, which have a value of $17.2 \mathrm{~dB}(\mathrm{~A})$.

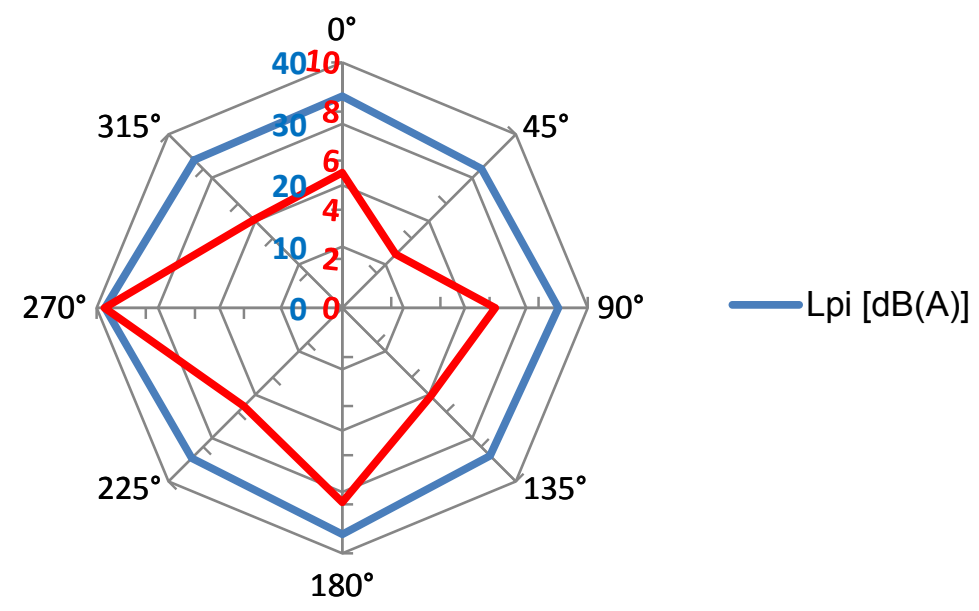

Fig. 4. Sound pressure level and directivity factor for sample PII.

In Figure 4, due to the use of sound-absorbing material, even if directivity factor has an irregular distribution, it can be seen a considerable reduction of the noise level emitted by the acoustic source and uniformity of sound pressure level curve around the noise source.

\section{CONCLUSIONS}

The importance of sound-absorbing material thickness used for encapsulation of electric motors is clear from evolving directivity factor inversely proportional to material thickness.

Note that there is a correlation between the directivity factor and sound pressure level curves measured. Directivity curve has lower levels as the degree of isolation of sound-absorbing material increases. This situation is encountered with increasing thickness of the insulation. To reduce noise from such sources - electric motors, it is recommended encapsulation solutions like those shown.

The experimental results are found as a simple solution encapsulation with sheet metal, such as the PI has a beneficial influence on noise emissions, lowering acoustic power level from P0 situation - without encapsulation with $8.88 \mathrm{~dB}$.

Depending on the insulation material used for encapsulation noise source, it is observed that the addition of sound absorbing material attached to the walls of the housing (housing lining) obtain a signification reduction of acoustic power emitted from $50.94 \mathrm{~dB}$ to $39.99 \mathrm{~dB}$ between PI and PII cases.

By comparison, considering the sound power noise source without encapsulation (P0 case, worst case) and combined encapsulation situation (where PII) with $1.5 \mathrm{~mm}$ sheet metal and sound-absorbing and sound-insulating material consists of material recyclable textile, differences can be seen very high sound pressure level measured around the source, and a sharp decline of nearly $20 \mathrm{~dB}$ of acoustic power emitted from $59.82 \mathrm{~dB}$ to $39.99 \mathrm{~dB}$. 
Thus, may conclude that the use of these materials with high absorption properties for designing and building carcasses have a beneficial effect in reducing noise pollution due to noise sources, as exemplified in this paper, if encapsulation of an electric motor.

In other types of electric motors or heating, which in the normal operation occurs heat release considerably high, the material type sound absorbing felt in encapsulation to reduce noise levels outside must take into account the resistance properties fire coefficient of thermal conductivity etc.

It still studying behavior and other sound-absorbing material, even composite laminates made from layers of material originally studied.

ACKNOWLEDGEMENT. The authors acknowledge the support of the Polytechnic University of Bucharest, Department of Mechanic, Laboratory of Acoustics and Vibration, where have been achieved experimental tests.

\section{REFERENCES}

[1] Beranek, L., The noise problem in the textile industry, Textile Industries, S.U.A., 134, no. 6, 1970.

[2] Darabont, A., Mijloace moderne de combatere a zgomotului si vibratiilor, Central Institute of Technical Documentation, Bucharest, 1971.

[3] Tiuc, A., Vasile, O., Gabor, T., Determination of antivibrational and acoustical properties of some materials made from recycled rubber particles and sawdust, Romanian Journal of Acoustics and Vibration, vol. XI, no. 1, 2014, p. 47-52.

[4] Lee, Y., Joo, C., Sound absorption properties of recycled polyester fibrous assembly absorbers, Autex Research Journal, vol. 3, no. 2, 2003.

[5] Gheorghe, A., Borlea (Tiuc), A., Evaluation of absorbing performances for composite plates made from recycled waste, SISOM 2012 and Session of the Commission of Acoustics, Bucharest, p. 307-313, 2012.

[6] Zhou, H., Li, B., Huang, G., He, J., A novel composite sound absorber with recycled rubber particles, Journal of Sound and Vibration, no. 304, 2007, p. 400-406.

[7] Terciu, O.M., Curtu, I., Cerbu, C., Stan, G.I., Research on mechanical properties of composites materials reinforced with lignocellulosic fibers, The 8th International Conference "Wood Science And Engineering In The Third Millenium", Icwse, Brasov, Romania, 2011, p. 345-352.

[8] Koizumi, T., Tsujiuchi, N., Adachi, A., The development of sound absorbing materials using natural bamboo fibers, High Performance, WIT Press, 2002.

[9] Fatima, S., Mohanty, A.R., Acoustical and fire-retardant properties of jute composite materials, Applied Acoustics, no. 72, 2011, p. 108-114.

[10] Curtu, I., Stanciu, M.D., Cosereanu, C., Vasile, O., Assessment of acoustic properties of biodegradable composite materials with textile inserts, Materiale plastice 49, no. I, 2012, p. 68-72.

[11] Bratu, P., Tracing curves for the sound absorbing characteristics in case of composites consisting of textile materials, Romanian Journal of Acoustics and Vibrations, vol. 4, no. 1, 2007, p. 23-26.

[12] Ersoy, S., Kucuk, H., Investigation of industrial tea-leaf-fibre waste material for its sound absorption properties, Applied Acoustics, no. 70, 2009, p. 215-220.

[13] Nastac, S., Anghelache, D., Stanciu, M., Curtu, I., On acoustic panels with high performances for pollutant individual working place insulation, 8th International DAAAM Baltic Conference Industrial Engineering, Tallinn, Estonia, 2012, p. 69-73.

[14] Anghelache, D., About phonic isolation of the mobile equipment cabin, The Annals of "Dunarea de Jos" University of Galati, Fascicle XIV Mechanical Engineering, vol. 1, 2008.

[15] Bratu, P., Dragan, N., Vasile, O., Experimental studies of sound absorption coefficient of composite materials used for acoustic treatments of the cabins, in the 11-th International Congress on Automotive and Transport Engineering CONAT 2010, Proceedings - volume III “Automotive Vehicles and Environment", p. 177-181, 2010. [16] SR EN ISO 3745:2012 Acoustics - Determination of sound power levels and sound energy levels of noise sources using sound pressure - Precision methods for anechoic rooms and hemi-anechoic rooms.

[17] SR EN ISO 11654:2002 Acoustics. Acoustic absorbers for use in buildings. Evaluation of acoustic absorption.

[18] Bratu, P., Acustica interioara pentru constructii si masini, Ed. Impuls, Bucuresti, 2002.

[19] Enescu, N., Magheti, I., Sarbu, M.A., Acustica tehnica, Ed. ICPE, Bucuresti, 1998.

[20] Vasile, O., Acustica tehnica - Indrumar de laborator, Ed. Politehnica Press, Bucuresti, 2013. 